\title{
Analisis Video Likes to Video Views Ratio Tiktok Pada 5 Artis Tiktok dengan Followers Terbanyak Di Tahun 2021
}

\author{
Putu Rian Kertayasa, 19101060 \\ ryankertayasa@gmail.com
}

\begin{abstract}
ABSTRAK
Tiktok merupakan salah satu platform sosial media dengan yang perkembangannya paling cepat didunia. Tiktok memungkinkan penggunanya untuk membuat vido pendek berdurasi 15 detik sampek 1 menit yang disertai dengan berbagai jenis music, filter, efek dan juga lypsinc yang digunakan untuk dikembangkan agar dapat mendukung kreatifitas penggunanya. Aplikasi sosial media Tiktok ini di dunduh lebih dari 30,7 juta pengguna yang aktif di Indonesia sehingga menjadikan Indonesia sebagai negara dengan pengguna Tiktok terbesar di dunia. Banyaknya pengguna Tiktok saat ini membuat Tiktok jadi terkenal dan memiliki jutaan followers setia. Hal ini membuka peluang bagi pengguna Tiktok untuk bisa menghasilkan uang melalui mengunggah video-video menghibur atau berbagai konten video menarik sebagai artis Tiktok. Adapun 5 artis Tiktok dengan followers terbanyak 2021 yaitu Sandys.ss, Cahyanirynn, Ria Ricis, jharna bhagwani, dan salhaerid. Tujuan dari penelitian ini yaitu untuk menghitung kredibilitas dari performa akun Tiktok 5 Artis Tiktok tersebut. Hasil dari penelitian ini menunjukan bahwa artis Tiktok Sandys.ss mendapatkan peringkat pertama dan memiliki kredibilitas performa akun yang baik.
\end{abstract}

Kata Kunci : Kredibilitas Akun Tiktok ; Social Media Tiktok ; Video Likes to Video Views Ratio ; Artis Tiktok.

\begin{abstract}
Tiktok is one of the fastest growing social media platforms in the world. Tiktok allows users to create short videos lasting from 15 seconds to 1 minute accompanied by various types of music, filters, effects and also lypsinc which is used to be developed in order to support the creativity of its users. This Tiktok social media application has been downloaded by more than 30.7 million active users in Indonesia, making Indonesia the country with the largest Tiktok users in the world. The number of Tiktok users currently makes Tiktok famous and has millions of loyal followers. This opens up opportunities for Tiktok users to be able to make money by uploading entertaining videos or various interesting video content as Tiktok artists. The 5 Tiktok artists with the most followers in 2021 are Sandys.ss, Cahyanirynn, Ria Ricis, jharna bhagwani, and salhaerid. The purpose of this study is to calculate the credibility of the Tiktok 5 Artist's account performance. The results of this study indicate that the Tiktok artist Sandys.ss gets the first rank and has good credibility for account performance.
\end{abstract}

Keywords : Tiktok Account Credibility; Social Media Tiktok ; Video Likes to Video Views Ratio ; Tiktok Artist. 


\section{PENDAHULUAN}

Perkembangan teknologi yang sangat pesat di era globalisasi saat ini telah memberikan banyak manfaat dalam kemajuan di berbagai aspek sosial, salah satunya adalah berkomunikasi menjadi lebih mudah dan cepat. Seiring dengan pesatnya perkembangan teknologi, komunikasi antar remaja di lingkungan sosial maupun sekarang sudah menguasai ilmu teknologi yang mengunakan jaringan internet, yaitu media social (Oktaheriyani, Wafa, and Shadiqien, n.d.). Media sosial merupakan sarana untuk melakukan komunikasi dan informasi dalam kehidupan manusia seperti whatsapp, instagram Tiktok, facebook, youtube dan lain sebagainya. Pada masa pandemi saat ini ada salah satu media sosial yang sangat banyak di gunakan atau sedang populer yaitu aplikasi Tiktok.

Di indonesia pada tahun 2018 aplikasi ini dinobatkan sebagai aplikasi terbaik di Play store yang dimiliki oleh Google. Tidak hanya itu, Tiktok juga menjadi kategori aplikasi paling menghibur (D. Putri and Adawiyah 2020). Tiktok memungkinkan pengguna untuk secara cepat dan mudah membuat video-video pendek yang unik untuk kemudian dibagikan ke teman-teman dan dunia. Memberdayakan pemikiran-pemikiran yang kreatif sebagai bentuk revolusi konten, menjadikan media sosial ini sebagai sebuah wujud tolak ukur baru dalam berkreasi bagi para online content creators di seluruh dunia, terutama Indonesia (Oktaheriyani, Wafa, and Shadiqien, n.d.). Menjadi content creator dapat dilakukan siapa saja dengan membuat video seperti tarian, gaya bebas, vlog, lipsync, dan masih banyak lagi. Dengan fitur-fitur yang disediakan, Tiktok dapat membuat mood penggunanya menjadi lebih baik. Hal ini membuat kami tertarik untuk mempelajari keunggulan dan kekurangan aplikasi Tiktok, apakah bermanfaat atau berdampak buruk bagi masyarakat (Saputra, Dhuatu, and Giyato 2020).

Semakin populernya aplikasi Tiktok ini menjadi aplikasi favorit baru bagi para pengguna media sosial khususnya Instagram, dengan tujuan agar video-video pendek tersebut setelah diunggah dapat dilihat oleh pengikutnya (followers), dan tidak sedikit yang akhirnya banyak yang mengagumi atau menyukai kiriman video-video tersebut sehingga menjadi booming serta membuat banyak orang humming bahkan terdapat fenomena munculnya seleb Tiktok atau artis Tiktok (Akademi et al. 2018). kehadiran artis Tiktok saat ini memunculkan beberapa pendapat mengenai siapa artis Tiktok dengan banyak followers di tahun 2021 contohnya saja seperti pemilik akun Sandys.ss, Jharna Bhagwani, Cahyanirynn, Ria Ricis, Saalhaerid, dan artis Tiktok lainnya ( 5 Artis Tiktok dengan Followers Terbanyak 2021, edisi 27 mei 2021 - suara.com ).

Penelitian ini menggunakan metode ekploratif kuantitatif dan akan menghitung menggunakan rasio-rasio yang ada pada Tiktok. Pada sosial media Tiktok terdapat 17 rasio dan relevan digunakan sebagai media hitung kredibilitas akun yang ada. Penelitian ini hanya berfokus untuk menghitung kredibilitas Video Likes to Video Views Ratio pada 5 artis Tiktok dengan followers terbanyak tahun 2021. Tujuan dari penelitian ini adalah mengetahui kredibilitas performa dari akun Tiktok 5 artis Tiktok dengan followers terbanyak tahun 2021 menggunakan Video Likes to Video Views Ratio. 


\section{TINJAUAN PUSTAKA}

Perkembangan bidang teknologi saat ini terjadi begitu pesat. Melalui perkembangan yang terjadi dari waktu ke waktu menimbulkan maraknya aplikasi-aplikasi serta platform media sosial yang bermunculan. Aplikasi yang sangat diminati oleh masyarakat saat ini diantaranya adalah Tiktok, Instagram, Twitter, WhatsApp dan yang lain sebagainya. Seiring berjalannya waktu, aplikasi sosial media tersebut dapat menjadi candu bagi kalangan masyarakat. Tidak hanya kalangan remaja yang menggunakan aplikasi sosial media, orang tua bahkan anak-anak juga aktif menggunakan aplikasi sosial media tersebut (Putu and Meinarni 2021).

Menurut Tim Pusat Humas Kementrian Perdagangan RI, menyatakan bahwa "media sosial adalah sebuah media online, dimana para penggunanya (user) melalui aplikasi berbasis internet dapat berbagi, berpartisipsi, dan menciptakan konten berupa blog, wiki, forum, jejaring sosial, dan ruang virtual yang disokong oleh tekhnologi multimedia yang kian canggih" (Akademi et al. 2018).

Aplikasi Tiktok merupakan salah satu aplikasi dalam telepon pintar berbasis media sosial yang memberikan keleluasaan bagi penggunanya, terutama dalam mengekspresikan diri. Tiktok merupakan salah satu media sosial yang memungkinkan penggunanya untuk menciptakan konten variatif seperti konten komedi, edukasi, tantangan (challenge), serta tarian (dance) dengan memanfaatkan fitur berupa penyuntingan dan pembuatan video. Aplikasi buatan ByteDance, perusahaan internet di Beijing ini selalu digemari oleh para pengguna yang berasal dari kalangan anak muda karena fiturnya yang mudah digunakan untuk membuat video dan musik kreatif (Indonesia, n.d.).

Salah satu ciri khas sosial media Tiktok adalah halaman utamanya yang Bernama For Your Page atau FYP. Pengguna yang cukup sering ditayangkan dalam FYP dapat menjadi populer dan memiliki banyak pengikut, yang biasa disebut sebagai seleb Tiktok (S. D. Putri and Azeharie 2021). Selain itu, melalui aplikasi Tiktok, Jika diamati mayoritas masyarakat menggunakan aplikasi Tiktok sebagai sarana untuk mengekspresikan diri sesuai dengan mood nya kala itu. Dalam aplikasi Tiktok terjadi interaksi dengan menggunakan komunikasi simbolik. Terlihat dari gestur tubuh, raut wajah, sinkronisasi bibir (Luh and Eka, n.d.). Pemanfaatan waktu luang dengan menggunakan Tiktok juga dimanfaatkan oleh beberapa penggunanya untuk menciptakan identitas mereka yang lain dari diri yang berada di dunia nyata.

Tiktok dirasakan memiliki kekuatan ataupun pengaruh dalam industri, sehingga menimbulkan kualitas akun yang menentukan strata maupun kredibilitas pemilik akun. Kredibilitas akun Tiktok merupakan suatu hal yang cukup penting untuk berbagai kepentingan. Kredibilitas sebuah akun Tiktok dapat diukur dari tingkat performa yang dihasilkan secara matematis. Dalam mengukur performa diperlukan skala pengukuran yang tertuang ke dalam rasio. 


\section{METODE PENELITIAN}

Penelitian ini menggunakan metode eksploratif kuantitatif untuk mengetahui kredibilitas dari performa 5 akun artis Tiktok dengan follower terbanyak di tahun 2021. Metode eksploratif merupakan penelitian yang memiliki tujuan untuk melakukan eksplorasi atau memperdalam pengetahuan ataupun ide-ide baru mengenai suatu hal yang baru, guna merumuskan permasalahan secara terperinci (Putu and Meinarni 2021).

Tujuan dari penelitian ini yaitu mengetahui nilai kredibillitas dari performa 5 akun artis Tiktok dengan follower terbanyak di tahun 2021. Ada beberapa langkah yang harus dilakukan dalam penelitian ini, sehingga mampu menemukan peringkat pertama 5 akun artis Tiktok dengan follower terbanyak di tahun 2021 yang memiliki performa terbaik. Langkahlangkah yang dilakukan pada penelitian ini, diantaranya yaitu :

\section{Melakukan Eksplorasi Pada Website Untuk Menentukan Objek yang Akan Dianalisa.}

Eksplorasi ini dilakukan pada beberapa halaman website yang menyediakan informasi mengenai objek yang akan di teliti. Setelah ekslorasi selesai dilakukan, sehingga ditemukan 5 akun artis Tiktok yang akan dijadikan objek analisa. Setelah melakukan eksplorasi pada halaman website, maka langkah selanjutnya yaitu mencari nama akun Tiktok dari masing-masing akun artis Tiktok tersebut. Pastikan semua artis Tiktok memiliki akun pada aplikasi sosial media Tiktok.

\section{Menghitung Nilai Rata-Rata Variable Dari 5 akun artis Tiktok dengan follower terbanyak di tahun 2021}

Pada langkah ini, peneliti menghitung nilai variable video likes dan variable video views. Variabel merupakan sesuatu yang memiliki nilai bervariasi dimana nilai tersebut dapat dijadikan sebagai dasar untuk empat data yang berbeda seperti rasio, skala, ordinal, nominal dan internal (Rankuti 2015; Putu and Meinarni 2021). Untuk menghitung nilai rata-rata dari variabel video likes dan variabel video views yaitu dengan cara mengambil minimal 10 postingan kemudian di hitung sehingga menemukan nilai rata-rata dari masing-masing variabel. 


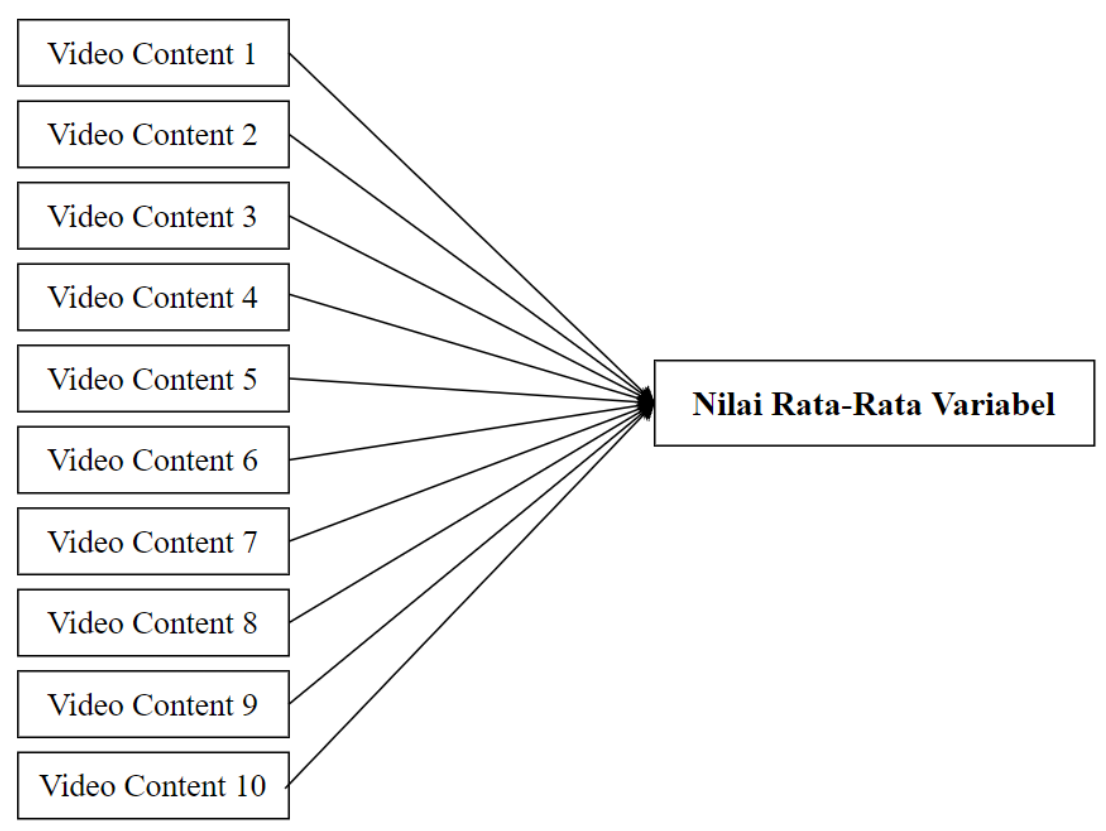

Gambar 1. Analisa Nilai Rata-Rata Variabel.

\section{Menghitung Nilai Kredibilitas Rasio}

Untuk menghitung nilai kredibilitas dari video likes to video views ratio, peneliti menggunakan cara membagi nilai variabel pertama dengan nilai variabel kedua. Jika video comments memiliki nilai 100 dan video views memiliki nilai 300, maka cara menghitungnya yaitu $100: 300=0,3$. Dengan begitu nilai dari video likes to video views ratio adalah 0,3 .

\section{Menentukan Peringkat Pada Akun Tiktok}

Pada langkah terakhir yang dilakukan pada penelitian ini yaitu menentukan peringkat pada masing-masing rasio yang ada. Pada penentuan peringkat perlu melihat karakteristik dari rasio yang di teliti. Jika karakteristik rasio merupakan rendah, maka objek yang memiliki nilai terendah akan mendapatkan angka 5 dan objek yang memiliki nilai tertinggi akan mendapatkan angka 1 . Namun jika rasio memiliki karakteritik tinggi maka objek yang mendapatkan nilai tinggi akan mendapatkan angka 5 dan objek yang mendapatkan nilai terendah akan mendapatkan angka 1. Setelah mendapatkan hasil kredibilitas ratio maka dapat disimpulkan objek yang mana mendapatkan peringkat 1 sampai dengan peringkat 5 . 


\section{HASIL DAN PEMBAHASAN}

5 ARTIS TIKTOK DENGAN FOLLOWERS TERBANYAK 2021, diantaranya :

\section{Sandys.ss}

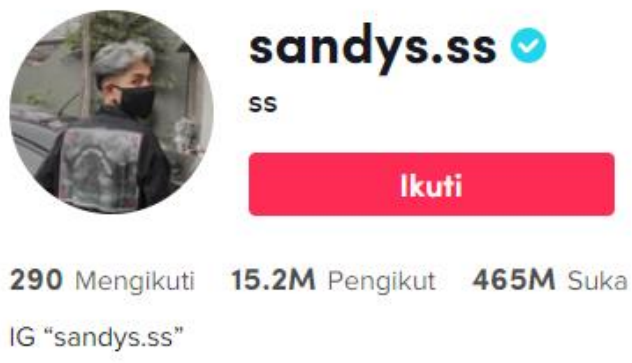

Gambar 1. Akun Tiktok Sandys.ss

Sumber : https://www.Tiktok.com/@sandys.ss (akses pada 06-10-2021)

\section{Cahyanirynn}

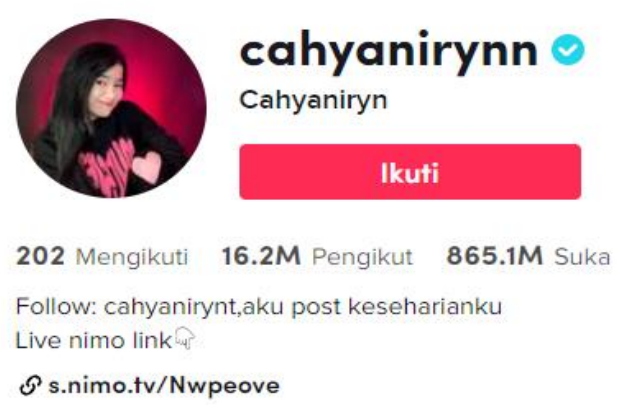

Gambar 2. Akun Tiktok cahyanirynn

Sumber : https://www.Tiktok.com/@cahyanirynn (akses pada 06-10-2021) 


\section{Ria Ricis}

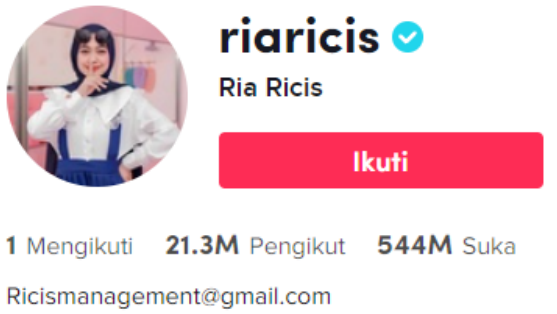

Gambar 3. Akun Tiktok Ria Ricis

Sumber : https://www.Tiktok.com/@riaricis (akses pada 06-10-2021)

\section{Jharna Bhagwani}

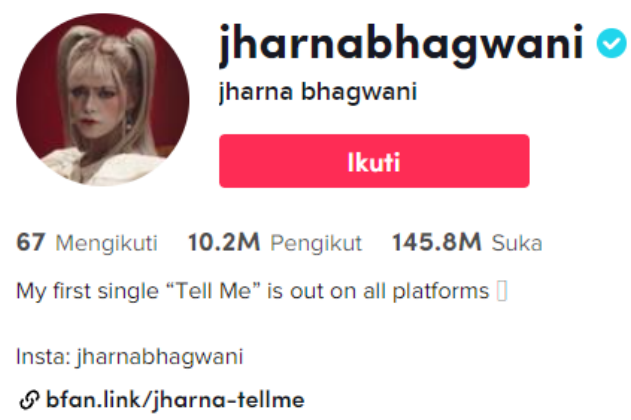

Gambar 4. Akun Tiktok jharnabhagwani

Sumber : https://www.Tiktok.com/@jharnabhagwani (akses pada 06-10-2021)

\section{Saalhaerid}

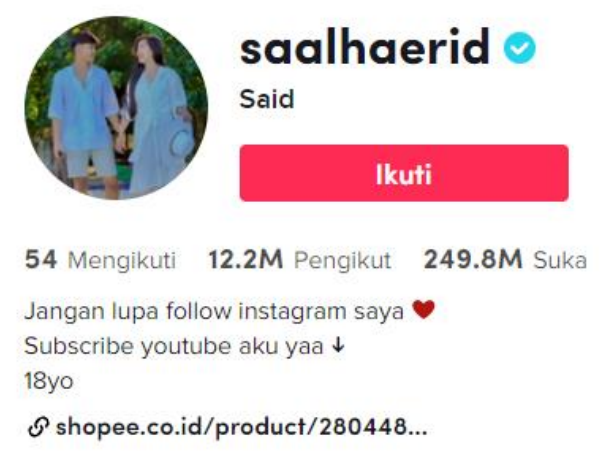

Gambar 5. Akun Tiktok Realme Indonesia

Sumber : https://www.Tiktok.com/@ saalhaerid (akses pada 06-10-2021) 
Dari kelima akun Tiktok Artis dengan Followers Terbanyak Tahun 2021, peneliti menemukan nilai dari masing-masing variabel yang ada untuk menghitung rasio Video Likes to Video Views dari setiap akun. Pada akun Tiktok terdapat 7 variabel, diantaranya yaitu :

1. Likes

2. Followers

3. Following

4. Video Likes

5. Video Comments

6. Video Share

7. Video Views

Dari ketujuh variabel tersebut peneliti hanya fokus untuk menemukan hasil dari 2 variabel, yaitu :

\section{Video Likes \\ 2. Video Views}

Dari kedua variabel tersebut kemudian dianalisa sehingga menemukan nilai rata-rata dari variabel video likes dan variabel video views. Untuk menghitung nilai rata-rata dari variabel video likes dan variabel video views yaitu dengan cara mengambil minimal 10 postingan kemudian di hitung sehingga menemukan nilai rata-rata dari masing-masing variabel. Berikut merupakan tabel nilai rata-rata dari masing-masing akun Tiktok 5 artis Tiktok dengan followers terbanyak di tahun 2021, yaitu :

Tabel 1. Analisa Nilai Rata-Rata Nilai Variabel Video Likes dan Video Views Akun Tiktok sandys.ss

\begin{tabular}{|c|c|c|}
\hline No & Video Like & Video Views \\
\hline 1 & 68.800 & 376.400 \\
\hline 2 & 16.000 & 109.800 \\
\hline 3 & 43.100 & 236.000 \\
\hline 4 & 48.800 & 255.400 \\
\hline 5 & 55.800 & 310.600 \\
\hline 6 & 20.200 & 131.800 \\
\hline 7 & 62.000 & 391.100 \\
\hline 8 & 78.600 & 488.000 \\
\hline 9 & 51.300 & 275.600 \\
\hline 10 & 72.900 & 331.900 \\
\hline Rata-rata & $\mathbf{5 7 . 5 2 5}$ & $\mathbf{2 9 0 . 6 6 0}$ \\
\hline
\end{tabular}


Tabel 2. Analisa Nilai Rata-Rata Nilai Variabel Video Likes dan Video Views Akun Tiktok Cahyanirynn

\begin{tabular}{|c|c|c|}
\hline No & Video Like & Video Views \\
\hline 1 & 90.800 & 511.600 \\
\hline 2 & 428.000 & 2.800 .000 \\
\hline 3 & 126.400 & 778.200 \\
\hline 4 & 42.000 & 280.100 \\
\hline 5 & 39.900 & 265.200 \\
\hline 6 & 356.400 & 2.800 .000 \\
\hline 7 & 96.400 & 554.900 \\
\hline 8 & 47.300 & 291.800 \\
\hline 9 & 68.200 & 400.800 \\
\hline 10 & 220.600 & 1.200 .000 \\
\hline Rata-rata & $\mathbf{1 5 1 . 6 0 0}$ & $\mathbf{9 8 8 . 2 6 0}$ \\
\hline
\end{tabular}

Sumber : Pengolah Data Excel

Tabel 3. Analisa Nilai Rata-Rata Nilai Variabel Video Likes dan Video Views Akun Tiktok Ria Ricis

\begin{tabular}{|c|c|c|}
\hline No & Video Like & Video Views \\
\hline 1 & 500.700 & 4.300 .000 \\
\hline 2 & 808.600 & 6.100 .000 \\
\hline 3 & 998.400 & 13.700 .000 \\
\hline 4 & 307.500 & 2.400 .000 \\
\hline 5 & 274.700 & 1.900 .000 \\
\hline 6 & 878.800 & $6.400,000$ \\
\hline 7 & 248.200 & 1.900 .000 \\
\hline 8 & 1.200 .000 & 10.700 .000 \\
\hline 9 & 230.500 & 1.600 .000 \\
\hline 10 & 1.500 .000 & 14.100 .000 \\
\hline Rata-rata & $\mathbf{6 9 4 . 7 4 0}$ & $\mathbf{6 . 3 1 0 . 0 0 0}$ \\
\hline
\end{tabular}

Sumber : Pengolah Data Excel 
Tabel 4. Analisa Nilai Rata-Rata Nilai Variabel Video Likes dan Video Views Akun Jharna Bhagwani

\begin{tabular}{|c|c|c|}
\hline No & Video Like & Video Views \\
\hline 1 & 13.500 & 246.600 \\
\hline 2 & 81.200 & 820.200 \\
\hline 3 & 120.300 & 827.600 \\
\hline 4 & 179.600 & 1.200 .000 \\
\hline 5 & 67.900 & 528.000 \\
\hline 6 & 1.600 .000 & 8.400 .000 \\
\hline 7 & 197.700 & 1.500 .000 \\
\hline 8 & 106.400 & 990.000 \\
\hline 9 & 88.300 & 726.200 \\
\hline 10 & 704.000 & 3.700 .000 \\
\hline Rata-rata & $\mathbf{3 1 5 . 8 9 0}$ & $\mathbf{1 . 8 9 3 . 8 6 0}$ \\
\hline
\end{tabular}

Sumber : Pengolah Data Excel

Tabel 5. Analisa Rata-Rata Nilai Variabel Video Likes dan Video Views Akun Tiktok Saalhaerid

\begin{tabular}{|c|c|c|}
\hline No & Video Like & Video Views \\
\hline 1 & 82.500 & 631.500 \\
\hline 2 & 53.800 & 289.400 \\
\hline 3 & 125.200 & 1.200 .000 \\
\hline 4 & 121.400 & 721.900 \\
\hline 5 & 21.300 & 109.600 \\
\hline 6 & 30.700 & 168.200 \\
\hline 7 & 743 & 8.104 \\
\hline 8 & 1151 & 9.162 \\
\hline 9 & 1107 & 6.537 \\
\hline 10 & 38.500 & 173.100 \\
\hline Rata-rata & $\mathbf{4 7 . 6 4 1}$ & $\mathbf{3 3 1 . 7 5 1}$ \\
\hline
\end{tabular}

Sumber : Pengolah Data Excel

Setelah menghitung nilai rata-rata tersebut, maka akan menemukan hasil akhir nilai rata-rata dari variabel video likes dan variable video views. 
Tabel 6. Nilai Variabel Pada Akun Tiktok dari 5 Artis Tiktok dengan followers terbanyak di tahun 2021

\begin{tabular}{|c|c|c|c|}
\hline \multirow{2}{*}{ No. } & \multirow{2}{*}{ Akun Tiktok } & \multicolumn{2}{|c|}{ Variable } \\
\cline { 3 - 4 } & & Video Likes & Video Views \\
\hline 1 & Sandys.ss & 57.525 & 290.660 \\
\hline 2 & Cahyanirynn & 151.600 & 988.260 \\
\hline 3 & Ria Ricis & 694.740 & 6.310 .000 \\
\hline 4 & Jharna Bhagwani & 315.890 & 1.893 .860 \\
\hline 5 & Saalhaerid & 47.641 & 331.751 \\
\hline
\end{tabular}

Sumber : Pengolah Data Excel

Pada akun Tiktok terdapat 17 rasio yang relevan digunakan untuk mengukur kredibilitas pada masing-masing akun. Namun pada penelitian kali ini hanya berfokus untuk menghitung Video Likes to Video Views Ratio. Untuk menghitung kredibilitas dari masing-masing 5 akun Tiktok tersebut, peneliti menghitung dengan cara : variabel 1 akan dibagi dengan variabel 2, sehingga ditemukan hasil analisisa dari rasio tersebut.

Tabel 7. Hasil Perhitungan Rasio Akun Tiktok

\begin{tabular}{|c|c|c|c|}
\hline \multirow{2}{*}{ No. } & \multicolumn{3}{|c|}{ Tabel Ratio } \\
\cline { 2 - 4 } & Akun Tiktok & Video Likes to Video Views & Karakteristik \\
\hline 1 & Sandys.ss & 1.197911649 & Tinggi \\
\hline 2 & Cahyanirynn & 0,153400926 & Tinggi \\
\hline 3 & Ria Ricis & 0,110101426 & Tinggi \\
\hline 4 & Jharna Bhagwani & 0,166796912 & Tinggi \\
\hline 5 & Saalhaerid & 0,143604691 & Tinggi \\
\hline
\end{tabular}

Sumber : Pengolah Data Excel

Video likes to Video Views Ratio memiliki karakteristik yang tinggi, artinya semakin tinggi nilai yang dihasilkan maka semakin baik kredibilitas dari performa akun tersebut. Untuk memberikan peringkat pada masing-masing akun Tiktok tersebut, peneliti memberikan angka 5 kepada akun Tiktok yang mendapatkan nilai tertinggi dan angka 1 untuk akun Tiktok yang mendapatkan nilai terendah. Berikut merupakan tabel urutan nilai yang dihasilkan oleh masing-masing vendor smartphone. 
Tabel 8. Nilai Rasio Akun Tiktok dsri 5 Artis Tiktok dengan Followers Terbanyak di tahun 2021

\begin{tabular}{|l|c|c|c|c|c|}
\hline \multirow{2}{*}{ RATIO } & \multicolumn{5}{|c|}{ NILAI } \\
\cline { 2 - 6 } & Sandys.ss & Cahyanirynn & Ria Ricis & $\begin{array}{l}\text { Jharna } \\
\text { Bhagwani }\end{array}$ & Saalhaerid \\
\hline $\begin{array}{l}\text { Video Likes to Video } \\
\text { Views Ratio }\end{array}$ & 5 & 3 & 1 & 4 & 2 \\
\hline
\end{tabular}

Sumber : Pengolah Data Excel

Dari Tabel Nilai Rasio Akun Tiktok 5 Artis Tiktok dengan Followers Terbanyak di tahun 2021 dapat simpulkan bahwa akun Tiktok Sandys.ss mendapatkan nilai tertinggi untuk rasio Video likes to Video Views. Sedangkan akun Tiktok Ria Ricis mendapatkan nilai terendah untuk rasio ini. Jadi, pada penelitian ini Sandys.ss memiliki kredibilitas performa yang lebih baik dibandingkan dengan akun 5 artis Tiktok yang lainnya.

\section{KESIMPULAN}

Tujuan dari penelitian ini adalah mengetahui kredibilitas performa dari akun Tiktok 5 Artis Tiktok dengan Followers Terbanyak Di Tahun 2021 menggunakan Video likes to Video Views Ratio. 5 Artis Tiktok dengan Followers Terbanyak Di Tahun 2021 tersebut diantaranya : Sandys.ss, Cahyanirynn, Ria Ricis, Jharna Bhagwani, dan Saalhaerid. Dari kelima akun Artis Tiktok tersebut dapat disimpulkan bahwa :

1. Peringkat pertama diraih oleh akun Tiktok Sandys.ss dengan nilai tertinggi 1.197911649

2. Peringkat kedua diraih oleh akun Tiktok Jharna Bhagwani dengan nilai 0,166796912

3. Peringkat ketiga diraih oleh akun Tiktok Cahyanirynn dengan nilai 0,153400926

4. Peringkat keempat diraih oleh akun Tiktok Saalhaerid dengan nilai 0,143604691

5. Peringkat kelima diraih oleh akun Tiktok Ria Ricis dengan nilai terendah 0,110101426 


\section{DAFTAR PUSTAKA}

Luh, N., \& Eka, W. (n.d.). Interaksi Simbolik dalam Proses Komunikasi Nonverbal pada Aplikasi Tiktok. 14(1), 11-19.

Bulele, Y. N., \& Wibowo, T. (2020). Analisis Fenomena Sosial Media Dan Kaum Milenial: Studi Kasus Tiktok. Conference on Business, Social Sciences and Innovation Technology, 1(1), 565-572. http://journal.uib.ac.id/index.php/cbssit

Dan, T., Banjiri, T., Tiktok, F., Kom, S., Kom, M., \& Nugroho, R. D. W. I. (2021). Laporan pengabdian masyarakat. 13190102.

Denise, P., \& Uya, D. A. N. (2021). Kementerian pendidikan dan kebudayaan.

Impact, V., \& Volume, J. M. (2019). 128 |Jurnal Makna Volume 4, No. 1 Maret 2019. 4(1), $128-138$.

Weimann, G., \& Masri, N. (2020). Studies in Conflict \& Terrorism Research Note :

Spreading Hate on Tiktok Research Note : Spreading Hate on Tiktok. Studies in Conflict \& Terrorism, O(0), 1-14. https://doi.org/10.1080/1057610X.2020.1780027

Batam, U. I. (2020). ANALISIS FENOMENA SOSIAL MEDIA DAN KAUM MILENIAL : STUDI KASUS TIKTOK. 1, 565-572.

Purnamasari, N. P., \& Tutiasri, R. P. (2021). Analisis Resepsi Remaja Perempuan terhadap Gaya Hidup Berbelanja Fashion Melalui Tayangan Video 'Belanja Gak Aturan' dalam Akun Tiktok@ @andmadeshoesby. Jurnal Representamen, 7(01). https://doi.org/10.30996/REPRESENTAMEN.V7I01.5129

P3M STMIK Widya Cipta Dharma. (n.d.). SEBATIK VOL 25 NO 1 - Google Books. 2021.

Wijaya, M. H. dwi, \& Mashud, M. (2020). Konsumsi Media Sosial Bagi Kalangan Pelajar: Studi Pada Hyperrealitas Tik Tok. Al-Mada: Jurnal Agama, Sosial, Dan Budaya, 3(2), 170-191. https://doi.org/10.31538/ALMADA.V3I2.734

PRIANBODO, B. (2018). PENGARUH “TIKTOK” TERHADAP KREATIVITAS REMAJA SURABAYA.

Putri, S. D., \& Azeharie, S. (2021). Strategi Pengelolaan Komunikasi dalam Membentuk Personal Branding di Media Sosial Tiktok. Koneksi, 5(2), 280-288. https://doi.org/10.24912/KN.V5I2.10300

Saputra, V. R., Dhuatu, C. H., \& Giyato, G. (2020). Pemanfaatan Aplikasi Tiktok Sebagai Mood Booster (the Usage of Tiktok App To Increase Mood Level). Indonesian Fun Science Award, 2(1), 216-226. https://proceedings.sgu.ac.id/ifsj/index.php/ifsj/article/view/53

Akademi, S., Bsi, K., Sitasi, C., Aplikasi, P., Sebagai, T., Branding, P., Instagram, D., Deskriptif, S., Pada, K., \& Komunikasi, J. (2018). Pemanfaatan Aplikasi Tiktok Sebagai 
Personal Branding Di Instagram ( Studi Deskriptif Kualitatif Pada Akun @ bowo _ allpennliebe ). 9(2).

Oktaheriyani, D., Wafa, M. A., \& Shadiqien, S. (n.d.). MEDIA SOSIAL TIKTOK ( Studi Pada Mahasiswa Fakultas Ilmu Sosial dan Ilmu Politik UNISKA MAB Banjarmasin ).

Batam, U. I. (2020). ANALISIS FENOMENA SOSIAL MEDIA DAN KAUM MILENIAL : STUDI KASUS TIKTOK. 1, 565-572.

Ruth, D., \& Candraningrum, D. A. (n.d.). Pengaruh Motif Penggunaan Media Baru Tiktok terhadap Personal Branding Generasi Milenial di Instagram. 207-214.

Putri, D., \& Adawiyah, R. (2020). Pengaruh Penggunaan Aplikasi Tiktok Terhadap Kepercayaan Diri Remaja di Kabupaten Sampang. 14(2), 135-148.

Putu, N., \& Meinarni, S. (2021). Ratio Analysis on Tiktok ( Social Media ) for Qualitative Research Using Explorative Methods. 8, 30-38.

Komunikasi, D. I., Ilmu, F., Dan, S., Politik, I., \& Utara, U. S. (2019). Persepsi Masyarakat Terhadap Aplikasi Tik Tok ( Studi Deskriptif Kuantitatif Aplikasi Tik Tok di Kalangan Mahasiswa Jurusan Ilmu Komunikasi FISIP USU Stambuk 2015 dan 2016 ) Vionita Anjani.

Priambodo, B. (2018). Pengaruh “Tiktok” Terhadap Kreativitas Remaja Surabaya. Skripsi, 74.

Indonesia, C.-D. I. (n.d.). TIKTOK SEBAGAI KONSTRUKSI IDENTITAS PADA MASA PANDEMI COVID-19 DI INDONESIA Rifki Zamzam Mustaffa Program Pascasarjana Fakultas Ilmu Budaya Universitas Padjadjaran. 288-289. 